D.O.I.: $10.3895 /$ S1808-04482012000100012

\title{
UTILIZAÇÃO DO MÉTODO DE UNIDADE DE ESFORÇO DE PRODUÇÃO (UEP) PARA DETERMINAÇÃO DOS CUSTOS DE TRANSFORMAÇÃO DE UMA INDÚSTRIA DE VIDROS CURVADOS PARA REFRIGERADORES COMERCIAIS
}

\section{USING THE METHOD OF PRODUCTION UNIT EFFORT (UEP) FOR DETERMINATION OF COST OF PROCESSING OF A GLASS BENT FOR INDUSTRY COMMERCIAL REFRIGERATION}

\author{
Vinícius Costa da Silva Zonatto ${ }^{1}$; Márcia Zanievicz da Silva ${ }^{2}$; Jorge Ribeiro de Toledo Filho ${ }^{3}$; \\ Andréa Valderene Drebes ${ }^{4}$; \\ ${ }^{1}$ Universidade Regional de Blumenau - FURB - Blumenau - Brasil \\ viniciuszonatto@gmail.com \\ ${ }^{2}$ Universidade Regional de Blumenau - FURB - Blumenau - Brasil \\ marciaza@gmail.com \\ ${ }^{3}$ Universidade Regional de Blumenau - FURB - Blumenau - Brasil \\ jtoledo@furb.br \\ ${ }^{4}$ Faculdade Dom Alberto - FDA - Santa Cruz do Sul - Brasil \\ andreadrebes@domalberto.edu.br
}

\begin{abstract}
Resumo
Este estudo objetiva aplicar o método UEP para mensurar o custo de transformação do produto base, vidros curvados, em uma organização industrial, buscando identificar qual o custo de transformação consumido por esta linha de produtos. A pesquisa caracteriza-se como um estudo de caso, de natureza exploratória, com abordagem quantitativa dos dados. Os resultados encontrados indicam que o método UEP pode ser utilizado como sistema de custeio proporcionando às informações necessárias a identificação dos custos efetivamente gastos na transformação dos insumos em produto final. Os custos mais significativos na fabricação deste produto estão relacionados aos gastos com mão de obra. Conclui-se que a empresa apresenta um baixo custo de transformação, o que proporciona uma maior competitividade para a organização.
\end{abstract}

Palavras-chave: UEP, método de custeio, custo de transformação.

\section{Introdução}

As empresas atualmente enfrentam uma concorrência agressiva no mercado, bem como o ambiente em que estão inseridas está em constante modificação, provocando transformações nos seus sistemas produtivos. Deste modo, os gestores sentem a necessidade de controlar melhor seus custos de produção, a fim de avaliar, por exemplo, se o preço de venda praticado, além de cobrir os 
custos de produção, proporcionam valor agregado, garantindo a competitividade e perenidade da organização.

Neste contexto, uma das áreas relevante nas organizações do tipo industriais, é o setor de custos. Este por sua vez é o responsável por monitorar o processo produtivo como um todo e identificar os gargalos da produção. Contudo, para que se possa apurar adequadamente o custo da produção, torna-se necessário identificar o método de custeio mais adequado às necessidades informacionais preteridas pelo gestor.

Dentre os vários métodos de custeio existentes, o método UEP (Unidade de Esforço de Produção), proporciona além da identificação do custo de transformação dos produtos, uma análise sobre o esforço empregado em cada etapa da fabricação de um produto e os gargalos existentes na organização. O método UEP, utilizado por várias empresas de diversos setores, é um acompanhamento da produção por cada etapa até a sua entrega ao comprador. Nele ocorre a contagem do tempo empregado em cada posto produtivo (etapa da produção), pelo colaborador, máquinas e demais esforços utilizados na fabricação dos produtos, minimizando assim os problemas de rateios utilizados em outros métodos.

Nesta perspectiva, buscando contribuir para com a melhoria dos processos de gestão da empresa pesquisada, realizou-se este estudo, cujo tem por objetivo aplicar o método UEP para mensurar o custo de transformação do produto base, vidros curvados, em uma indústria sediada no município de Venâncio Aires/RS. O objetivo está direcionado a responder a seguinte questão de pesquisa: Qual o custo de transformação na linha de produtos vidros curvados, para refrigeradores comerciais, na empresa pesquisada?

Para tanto, de forma mais específica, buscou-se: apresentar o método UEP, suas características e abordagem; identificar os elementos de custos relacionados à fabricação de vidros curvados na empresa pesquisada; apurar o custo de transformação destes produtos utilizando o método UEP; e, analisar a contribuição deste método no processo decisório.

A pesquisa limita-se a estudar exclusivamente a aplicação deste método como sistema de custeio, sendo aplicado na principal linha de produção da empresa pesquisada. Visto que a gestão de custos contribui numa melhor análise dos processos de produção, subsidiando o processo decisório, apresenta-se como justificativa e contribuição desse estudo: [1] evidenciar uma aplicação prática que permita reflexões teóricas acerca da abordagem do método UEP como método de custeio; [2] incentivar a aplicação desta metodologia em outros estudos desta ordem, a fim de promover discussões correlatas sobre o tema; e, [3] contribuir para a melhoria dos processos de gestão da empresa pesquisada.

\section{A gestão de custos em empresas industriais}


Para Bornia (2009) a análise de um sistema de custos pode ser feita diante de dois pontos de vista, no primeiro momento, se o tipo de informação gerada está em acordo com as necessidades pretendidas e que tipo de informações importantes deveriam ser fornecidas, dando-se a denominação de princípio de custeio. No segundo momento a analise do processamento dos dados, sob denominação de método de custeio.

Em todas as empresas existem custos, tanto variáveis como fixos, mas se acentuam mais nas indústrias, onde são transformadas as matérias primas em produtos e, junto são consumidos materiais auxiliares, a mão de obra empregada, a energia elétrica em muitos casos, as depreciações das máquinas e equipamentos e demais gastos e desgastes que ocorrem durante o processo de produção.

Os custos variáveis, geralmente, são mais fáceis de serem identificados por meio de documentos fiscais e pelos demais valores pagos até a entrada dos materiais dentro do estabelecimento, oscilando em função das quantidades produzidas. Já os custos fixos, devem ser atribuídos aos produtos, porém, muitas vezes as empresas possuem dificuldade para tal, como fazer, como dividir e agregar a cada produto tais custos, o que não é possível de quantificar sem adotar um método. $\mathrm{O}$ custo total ocorreu e deve ser recuperado e integrar o custo total do produto fabricado. Uma má gestão dos custos poderá acarretar prejuízos à organização e dificuldades para competir no mercado.

Há inúmeras empresas que produzem vários tipos de produtos. Cada linha produzida demanda determinadas matérias-primas e diferentes custos de transformação. O gestor na hora de produzir necessita saber quanto custará cada produto para viabilidade de sua fabricação. $\mathrm{O}$ esforço empregado em cada linha de produtos pode alterar e, em virtude do tempo empregado, alterar também o custo de produção.

Os custos de fabricação do produto devem seguir um sistema para serem apropriados, como não são de fácil identificação, devem ser alocados de forma coerente e eficaz. Não basta somente saber quanto foi pago pela aquisição da matéria prima, precisa-se conhecer o custo total de produção, onde são englobados os custos fixos e variáveis.

\subsection{O método UEP}

De acordo com Gantzel e Allora (1996), a unidade de produção é um unificador dos controles de gestão produtiva das empresas, que, por meio de uma única unidade de medida, permite medir toda e qualquer produção, por mais diversificada que seja. Segundo Bornia (2009), o método UEP teve suas origens na França, mais especificamente na época da Segunda Guerra Mundial.

O método UEP, em primeira instância denominado como GP é um método de cálculo e 
alocação de custos e controle de gestão criado pelo francês Georges Perrin, que logo após o término da guerra abriu uma empresa de consultoria para a implantação do sistema que criou. Com a morte de Georges Perrin, o método veio a cair em esquecimento na França. Um discípulo seu, Franz Allora, na década de 60, modificou o método GP e denominou-o de Método UP (Unidades de Produção), ou também Método UEP (BORNIA, 2009).

O método da unidade de esforço de produção baseia-se na unificação da produção de empresas multiprodutoras por meio da definição de uma unidade de medida comum a todos os artigos da empresa: a UEP (BORNIA, 2002, p. 36). Wernke (2004, p. 36) explica que este método:

identifica a empresa como concebida, com o objetivo básico de transformar matéria-prima em produto final. Para tanto, as unidades produtivas realizam um esforço de produção nesta transformação. Este esforço, por sua vez, está associado a uma série de outros esforços parciais, que são, esforço das máquinas e equipamentos, esforço material, esforço humano e esforço utilidade.

No Brasil, até 1978 não houve muita aplicação dessa metodologia. Neste ano, foi criada uma empresa de consultoria em Blumenau/SC, onde a atividade se baseava na implantação desse sistema de custos, tendo sido aplicado em empresas das regiões de Blumenau e Joinville/SC.

Bornia (2009, p.137) destaca que, mais tarde, em 1986, uma equipe de pesquisadores da Universidade Federal de Santa Catarina (UFSC) passou a estudar, divulgar e aprimorar o método, dando uma efetiva divulgação em congressos e dissertações de mestrado, em especial na UFSC e Universidade Federal do Rio Grande do Sul (UFRGS).

Nesta perspectiva, Walter et al. (2009) destaca dentre os principais estudos realizados com esta abordagem, os trabalhos desenvolvidos por: Kliemann Neto (1994), Bornia (1994), Pereira, Rebelatto e Tachibana (2000), Sakamoto, Allora e Oliveira (2001) e Borgert e Silva (2005). A síntese destes estudos é evidenciada no Quadro 1.

Quadro 1 - Estudos destacados em pesquisa com a abordagem do método UEP

\begin{tabular}{|c|c|c|}
\hline Autores & Título do trabalho & Síntese do estudo \\
\hline $\begin{array}{l}\text { Kliemann } \\
\text { (1994) }\end{array}$ & $\begin{array}{l}\text { Gerenciamento e controle da } \\
\text { produção pelo Método das } \\
\text { Unidades de Esforço de Produção }\end{array}$ & $\begin{array}{l}\text { O autor descreve todas as bases teóricas do } \\
\text { método das UEPs, indicando suas aplicações para } \\
\text { custeio e gestão da produção. }\end{array}$ \\
\hline Bornia (1994) & $\begin{array}{l}\text { Utilização do Método da Unidade } \\
\text { de Esforço de Produção na } \\
\text { quantificação das perdas internas da } \\
\text { empresa }\end{array}$ & $\begin{array}{l}\text { Como contribuição às fundamentações teóricas do } \\
\text { método, o autor introduz seu uso para } \\
\text { quantificação de perdas na área produtiva. }\end{array}$ \\
\hline $\begin{array}{l}\text { Pereira, Rebelatto e } \\
\text { Tachibana (2000) }\end{array}$ & $\begin{array}{l}\text { Revisitando o Método das Unidades } \\
\text { de Esforço de Produção (Uep's): } \\
\text { algumas considerações quanto à sua } \\
\text { eficiência e eficácia como } \\
\text { instrumento de gestão }\end{array}$ & $\begin{array}{l}\text { O trabalho revisa e sistematiza as principais } \\
\text { contribuições relacionadas ao Método das UEP's } \\
\text { até então apresentadas nos Congressos Brasileiros } \\
\text { de Custos. }\end{array}$ \\
\hline $\begin{array}{l}\text { Sakamoto, Allora e } \\
\text { Oliveira (2001) }\end{array}$ & $\begin{array}{l}\text { Melhoramento nas ferramentas de } \\
\text { gestão: a implantação da Up'- } \\
\text { Unidade de Produção - na Seara } \\
\text { Alimentos S/A }\end{array}$ & $\begin{array}{l}\text { Esta obra descreve o processo de implementação } \\
\text { do método das UEPs em uma empresa } \\
\text { agroindustrial, fornecendo uma perspectiva do } \\
\text { ponto de vista dos profissionais envolvidos. }\end{array}$ \\
\hline $\begin{array}{l}\begin{array}{l}\text { Borgert } \\
(2005)\end{array} \\
\text { e Silva }\end{array}$ & $\begin{array}{l}\text { Método de custeio híbrido para } \\
\text { gestão de custos em uma empresa }\end{array}$ & $\begin{array}{l}\text { Neste estudo os autores propõem um método } \\
\text { híbrido UEP/Custeio Baseado em Atividades para }\end{array}$ \\
\hline
\end{tabular}




\begin{tabular}{|l|l|l|}
\hline & prestadora de serviços & $\begin{array}{l}\text { o custeio de serviços, sendo este um objeto de } \\
\text { custeio até então desconsiderado pela literatura. }\end{array}$ \\
\hline
\end{tabular}

Fonte: Adaptado de Walter et al. (2009)

Observa-se no Quadro 1, que a concepção do método UEP está focada no processo de gestão organizacional dos processos de produção. O foco no esforço efetivamente despendido na transformação de insumos em produtos permite ao gestor uma avaliação da empresa e sua eficiência produtiva, o que contribui no estabelecimento de vantagem competitiva. Na seqüência apresentamse as principais características do método UEP.

\subsection{Características do método UEP}

De acordo com Souza e Diehl apud Kraemer (1995, p. 181), “o método das UEP’s possui três princípios que o sustentam e que o viabilizam como método de gestão". São eles:

\begin{tabular}{|c|c|}
\hline & \\
\hline Princípio de valor agregado & $\begin{array}{l}\text { afirma que o produto de uma fábrica é o trabalho que se realiza sobre as } \\
\text { matérias-primas e se reflete no valor que este trabalho agrega a elas. De } \\
\text { acordo com esse princípio, o método das UEPs tratas as matérias-primas } \\
\text { como meros "objetos de trabalho". A unificação e o controle da produção } \\
\text { serão feitos em função dos esforços despendidos pelos diversos postos } \\
\text { operativos (PO - são os postos de trabalho onde os materiais são } \\
\text { processados) para a transformação das matérias-primas em produtos } \\
\text { acabados; }\end{array}$ \\
\hline $\begin{array}{l}\text { Princípio das relações } \\
\text { constantes }\end{array}$ & $\begin{array}{l}\text { os produtos, para serem processados, passam por diversos postos operativos. } \\
\text { Cada um desses possui uma capacidade de processamento, chamado } \\
\text { potencial produtivo. O princípio das relações constantes afirma que a relação } \\
\text { entre os potenciais produtivos de dois postos operativos se mantém constante } \\
\text { no tempo, mesmo em face das variações da conjuntura econômica. Em } \\
\text { outras palavras, o princípio das relaçôes constantes afirma que a relação } \\
\text { entre os custos de dois postos operativos medidos num tempo } 1 \text { permanecerá } \\
\text { constante para um tempo } 2 \text {, uma vez realizada a correção monetária dos } \\
\text { valores de custos; }\end{array}$ \\
\hline Princípio das estratificações & $\begin{array}{l}\text { afirma que para o cálculo dos potenciais produtivos dos postos operativos } \\
\text { apenas devem ser considerados os itens de custo na produção que } \\
\text { proporcionam algum grau de diferenciação entre esses postos operativos. } \\
\text { Portanto, esse princípio orienta a operacionalização do princípio das relações } \\
\text { constantes, alocando aos diversos postos operativos, por unidade de } \\
\text { capacidade (normalmente por hora), os valores dos itens de custo que } \\
\text { possibilitarão a compreensão sãs diferenças entre os esforços de produção } \\
\text { transferidos por eles aos produtos. }\end{array}$ \\
\hline
\end{tabular}

Fonte: Adaptado de Souza e Diehl apud Kraemer (1995, p. 181)

A característica do método UEP é o efetivo emprego do tempo utilizado para a obtenção do custo de produção. Tudo se baseia no tempo despendido, por isso a correta cronometragem do tempo da passagem em cada posto operativo. $\mathrm{O}$ resultado final do custo de produção deve ser o mais concreto possível.

O método UEP proporciona chegar ao custo de produção por um processo diferenciado, ou seja, por meio do esforço efetivamente empregado, o custo do tempo consumido por cada posto de produção. Quando há mais que uma linha de produto, em cada uma poderão ser computados os 
custos incorridos durante o processo de transformação.

Mesmo que a empresa tenha somente um produto, é necessário saber de todos os custos, tais como: mão de obra direta e indireta, encargos sociais, depreciações, materiais de consumo usados dentro da fábrica, peças e a manutenção dos equipamentos e demais gastos incorridos durante a produção. Após a obtenção de tais informações, segundo Oliveira e Beuren (1996):

\begin{abstract}
a produção da fábrica em UEP's é feita com a simples soma dos produtos por ela fabricados. Então, por meio da divisão do total dos custos totais de fabricação incorridos pelo valor total em UEP's, obtém-se o valor real e monetário de uma UEP. Após a obtenção deste, para se calcular o custo de cada produto, multiplica-se o seu valor em UEP's pelo valor monetário da UEP da fábrica (OLIVEIRA e BEUREN, 1996, p. 35).
\end{abstract}

\title{
3. Método e procedimentos da pesquisa
}

A metodologia utilizada para a realização da pesquisa se caracteriza como um estudo de caso de natureza exploratória, com abordagem quantitativa dos dados. Gil (2002, p.54) define o estudo de caso como "um estudo profundo e exaustivo de um ou poucos objetos, de maneira que permita seu amplo e detalhado conhecimento, tarefa praticamente impossível mediante outros delineamentos já considerados."

Com relação às pesquisas exploratórias, estas por sua vez têm por objetivo "proporcionar maior familiaridade com o problema, com vistas a torná-lo mais explícito ou a construir hipóteses. Pode-se dizer que essas pesquisas têm como objetivo principal o aprimoramento de idéias ou a descoberta de intuições" (GIL, 2002, p. 41).

Num primeiro momento, realizou-se uma pesquisa bibliográfica, com o intuito de fundamentar o estudo proposto. “A pesquisa bibliográfica é desenvolvida com base em material já elaborado, constituído principalmente de livros e artigos científicos" (GlL, 2002, p. 44). A seguir, para a coleta e análise dos dados, utilizou-se de uma abordagem quantitativa, que, segundo Richardson (1989, p. 29), “caracteriza-se pelo emprego da quantificação tanto nas modalidades de coleta de informações, quanto no tratamento dessas através de técnicas estatísticas".

Para a realização da coleta e análise dos dados, observaram-se as oito etapas propostas por Wernke (2004, p.34), para a implantação do método UEP. São elas: divisão da fábrica em postos operativos; determinação dos índices de custos horários por posto operativo FIPO (ou o Custo/hora por posto operativo); obtenção dos tempos de passagem dos produtos pelos postos operativos; escolha do produto-base; cálculo dos potenciais produtivos (UEP/hora) de cada posto operativo; definição dos equivalentes dos produtos em UEP (valor em UEP do produto); mensuração da produção total em UEP; e, cálculo dos custos de transformação.

Neste sentido, a pesquisa estabelece os postos operativos na empresa pesquisada, observando-se o processo de transformação dos vidros curvados. De acordo com Bornia (2002, p.145), “um Posto Operativo (PO) é composto de operações homogêneas, formado por uma ou mais 
operações de produção que apresentem características semelhantes para qualquer produto que por ali passem, diferenciando apenas no tempo".

Após a definição dos PO's, procurou-se identificar os índices de custos horários por posto operativo. Bornia (2002, p.145) "denomina esta determinação dos custos horários $(\$ / \mathrm{h})$ como foto índices, e são calculados de acordo com seu efetivo dispêndio de insumos por parte dos PO's em funcionamento". Tal procedimento se dá através do levantamento de insumos consumidos em cada local (PO) em determinado período, dividindo-se o valor obtido (em $\mathrm{R} \$$ ) dos custos de transformação destes, pela quantidade das horas efetivamente trabalhadas no mesmo.

De posse dessas informações, efetuaram-se os demais cálculos necessários para a análise dos dados e o alcance do objetivo da pesquisa. O estudo limita-se a analisar exclusivamente a aplicação do método UEP no processo de gestão de custos da empresa pesquisada, sendo aplicado na principal linha de produção da organização, denominada de produto base. A seguir, apresentam-se os resultados da pesquisa.

\section{Análise e interpretação dos resultados}

O trabalho reporta-se a um estudo de caso realizado na empresa aqui sob a denominação de Vidros Curvados do Sul Ltda., sediada na cidade de Venâncio Aires, interior do estado do Rio Grande do Sul. Os vidros adquiridos em chapas de diversos tamanhos e dimensões são a matériaprima preponderante da produção.

Atualmente a empresa apura seus custos com base nas aquisições dos insumos, agregando os demais gastos e despesas incorridos, sem muita profundidade. Mas, diante da necessidade de maiores controles, busca um sistema de custos que possibilite informações que lhe propicie diferenciais competitivos, a fim de manter-se sólida no mercado de atuação.

\subsection{Aplicação do método UEP na determinação dos custos de transformação}

A primeira etapa realizada para a análise do método UEP, na determinação dos custos de transformação da empresa pesquisada, foi a divisão da fábrica em postos operativos. A Figura 1 apresenta a empresa como um todo e a divisão proposta para o estudo. 
Figura 1 - Visão geral da fábrica e do processo produtivo

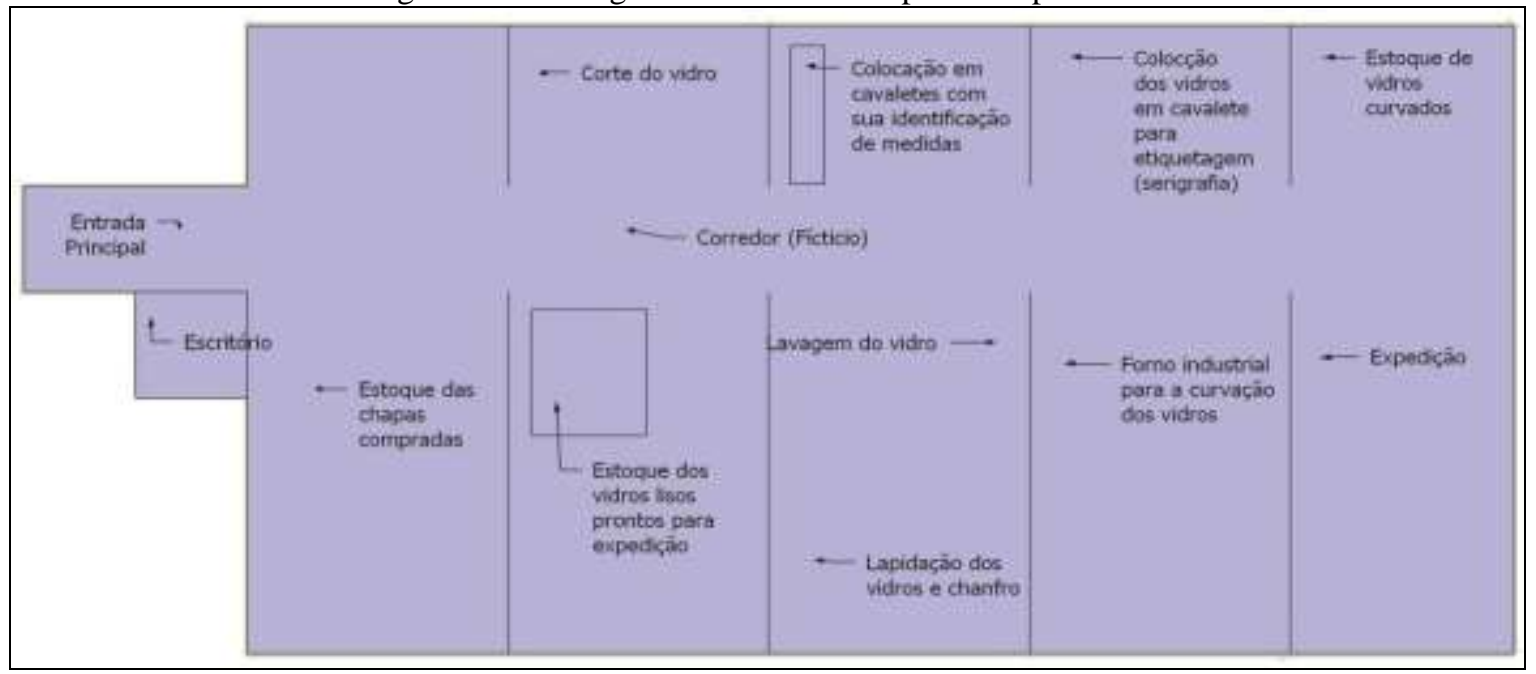

Fonte: Dados da pesquisa

Para a implantação do método UEP a empresa foi dividida em postos operativos. Conforme a ordem do processo produtivo efetuou-se a cronometragem das forças empregadas, bem como a identificação das máquinas e equipamentos empregados no processo de produção e o esforço humano despendido em cada PO. O Quadro 3 apresenta os resultados da divisão proposta na pesquisa.

Quadro 3 - Divisão da fábrica em postos operativos

\begin{tabular}{|c|l|l|c|}
\hline Códigos & \multicolumn{1}{|c|}{ Posto Operativo } & \multicolumn{1}{c|}{$\mathbf{N}^{\mathbf{o}}$ de Equip. } & Funcionários \\
\hline PO1 & Medição e Corte do Vidro & 1 Mesa de Corte & 3 \\
\hline PO2 & Etiquetagem e Armazenagem & 1 Cavalete & 1 \\
\hline PO3 & Lapidação e Chanfro & 2 Equipamentos & 3 \\
\hline PO4 & Lavagem e Secagem & 1 Equipamento & 3 \\
\hline PO5 & Etiquetagem & 1 Cavalete & 1 \\
\hline PO6 & Curvação & 1 Forno & 2 \\
\hline PO7 & Armazenagem & 1 Cavalete & 2 \\
\hline
\end{tabular}

Fonte: Dados da pesquisa

Observa-se, no Quadro 3, que os postos operativos foram estabelecidos de acordo com a linha de beneficiamento da empresa pesquisada. Em alguns casos, optou-se por agrupar máquinas e equipamentos, em virtude das operações serem semelhantes ou servirem de ligação de uma etapa para outra, como o caso das esteiras. Tal procedimento é adequado e não interfere na composição do custo final, uma vez que os valores serão considerados no processo de beneficiamento como um todo, conforme recomenda Bornia (2002).

Após a definição dos postos operativos, procurou-se identificar a quantidade de máquinas e colaboradores que cada posto possui. Nesta etapa, identificou-se que a empresa trabalha apenas em um turno, de segundas a sextas feiras, com jornada de trabalho diária de 08 horas e 45 minutos, sendo que o número de funcionários compõe o total da mão de obra disponível pela empresa em todos os postos operativos, nesta jornada de trabalho. 
De posse destas informações, se realizaram os cálculos necessários para a identificação dos custos de transformação, na empresa pesquisada, considerando os princípios do método UEP, por posto operativo. No Quadro 4 são destacados os custos de transformação ocorridos no período analisado em cada posto de operativo.

\begin{tabular}{|c|c|c|c|c|c|c|c|c|c|c|c|c|}
\hline \multirow{2}{*}{$\begin{array}{l}\text { Código } \\
\text { PO1 }\end{array}$} & \multicolumn{2}{|c|}{$\begin{array}{l}\text { MOD Propria } \\
\text { (R\$) }\end{array}$} & \multicolumn{2}{|c|}{$\begin{array}{l}\text { Depreciação } \\
\text { (R\$) }\end{array}$} & \multicolumn{2}{|c|}{$\begin{array}{c}\text { Energia } \\
\text { (R\$) }\end{array}$} & \multicolumn{2}{|c|}{$\begin{array}{l}\text { Manutenção } \\
\text { (R\$) }\end{array}$} & \multicolumn{2}{|c|}{$\begin{array}{l}\text { Outros } \\
\text { Equip. }\end{array}$} & \multicolumn{2}{|c|}{$\begin{array}{c}\text { Total dia } \\
\text { (R\$) }\end{array}$} \\
\hline & $\mathrm{R} \$$ & $1.905,75$ & $\mathrm{R} \$$ & 128,47 & $\mathrm{R} \$$ & 960,69 & $\mathrm{R} \$$ & 110,76 & $\mathrm{R} \$$ & 15,00 & $\mathrm{R} \$$ & $3.120,67$ \\
\hline $\mathrm{PO} 2$ & $\mathrm{R} \$$ & 635,25 & $\mathrm{R} \$$ & - & $\mathrm{R} \$$ & 320,23 & $\mathrm{R} \$$ & 36,92 & $\mathrm{R} \$$ & 5,00 & $\mathrm{R} \$$ & 997,40 \\
\hline PO3 & $\mathrm{R} \$$ & $1.905,75$ & $\mathrm{R} \$$ & 40,97 & $\mathrm{R} \$$ & 960,69 & $\mathrm{R} \$$ & 110,76 & $\mathrm{R} \$$ & 15,00 & $\mathrm{R} \$$ & $3.033,17$ \\
\hline PO4 & $\mathrm{R} \$$ & $1.905,75$ & $\mathrm{R} \$$ & 13,89 & $\mathrm{R} \$$ & 960,69 & $\mathrm{R} \$$ & 110,76 & $\mathrm{R} \$$ & 15,00 & $\mathrm{R} \$$ & $3.006,09$ \\
\hline PO5 & $\mathrm{R} \$$ & 635,25 & $\mathrm{R} \$$ & - & $\mathrm{R} \$$ & 320,23 & $\mathrm{R} \$$ & 36,92 & $\mathrm{R} \$$ & 5,00 & $\mathrm{R} \$$ & 997,40 \\
\hline PO6 & $\mathrm{R} \$$ & $1.270,50$ & $\mathrm{R} \$$ & 20,97 & $\mathrm{R} \$$ & 640,46 & $\mathrm{R} \$$ & 73,84 & $\mathrm{R} \$$ & 10,00 & $\mathrm{R} \$$ & $2.015,77$ \\
\hline PO7 & $\mathrm{R} \$$ & $1.270,50$ & $\mathrm{R} \$$ & 2,29 & $\mathrm{R} \$$ & 640,46 & $\mathrm{R} \$$ & 73,84 & $\mathrm{R} \$$ & 10,00 & $\mathrm{R} \$$ & $1.997,09$ \\
\hline Totais & $\mathbf{R} \$$ & $9.528,76$ & $\mathbf{R S}$ & 206,60 & $\mathbf{R} \$$ & $4.803,45$ & $\mathbf{R} \$$ & 553,80 & $\mathbf{R} \$$ & 75,00 & $\mathbf{R S}$ & $15.167,61$ \\
\hline
\end{tabular}

Em cada posto operativo, efetuou-se a contagem do tempo de cada etapa, onde foi apurado cada minuto gasto efetivamente no processo de transformação, levando-se em consideração o horário de trabalho dos colaboradores da organização.

O período base analisado refere-se a janeiro de 2010. Neste período, os colaboradores trabalharam apenas dezenove dias, onde foram excluídos os dias não trabalhados no mesmo, ou seja, cinco sábados, cinco domingos e dois feriados, sendo um o dia primeiro de janeiro como confraternização universal e o outro, o dia 20 de janeiro, feriado municipal.

Em seguida, foram apurados os valores dos salários e encargos sociais de cada colaborador envolvido no processo e apropriados em cada posto operativo (PO). Para dar prosseguimento aos cálculos, o somatório dos custos totais apurados com mão de obra direta foi dividido pelo número de horas efetivamente trabalhadas no mês usado como referência (janeiro de 2010).

Com base no custo com mão de obra apurado (tempo produtivo), foram apropriados os demais custos de produção consumidos durante o processo de transformação dos produtos (gastos com energia elétrica, manutenção de máquinas e equipamentos de proteção individual). Com relação à depreciação das máquinas, esta foi apropriada com base na utilização dos equipamentos (tempo/hora de utilização) em cada posto operativo.

As demais informações levantadas neste processo estão relacionadas ao produto "peça de vidro" usada como insumo na indústria de refrigeração. O produto final acabado, denominado vidro curvado, após sua transformação total, mede 1,90m x 85,50cm, com espessura de $5 \mathrm{~mm}$. Este é o principal produto comercializado pela organização, representando $85 \%$ da produção da empresa.

As demais peças resultantes da fabricação de produtos da empresa pesquisada variam de tamanho e formatos. São diversos modelos a serem seguidos e adaptados de acordo com as necessidades do cliente que faz a encomenda. Conforme o tamanho das chapas de vidros adquiridas 
para a produção, são empreendidos os esforços para o atendimento do pedido solicitado pelo cliente.

No estudo de caso elaborado, foi utilizada uma chapa de vidro medindo 2,20m x 3,21m, com desperdício de 5,59\% (apontado pelos funcionários). Com estas medidas foram extraídas 4 (quatro) peças, sendo que cada tempo empreendido no processo de produção deste produto, refere-se à produção de 4 (quatro) unidades de produto acabado.

Não é objeto deste estudo, a determinação do custo de produção destes produtos, mas sim, do custo de transformação consumido na empresa, no processo de beneficiamento destes insumos, que geram o produto final acabado. Logo, tal informação pode ser um interessante instrumento de gestão, proporcionando informações sobre o total gasto na transformação das matérias primas, bem como, o esforço consumido no decurso deste processo, servindo este como um indicador para a mensuração da produtividade na organização.

De posse dessas informações, realizou-se a apuração dos cálculos do custo hora (fotoíndices), conforme estabelecido por Wernke (2004), como parte do processo de implantação do método UEP. O Quadro 5 apresenta a síntese dos resultados encontrados na pesquisa.

Quadro 5 - Determinação dos custos hora (foto-índices)

\begin{tabular}{|c|rr|c|r|}
\hline Código & \multicolumn{2}{|c|}{$\begin{array}{c}\text { Gastos Totais } \\
\text { (R\$/dia) }\end{array}$} & Horas Trab. & Custo hora (R\$) \\
\hline PO1 & $\mathrm{R} \$$ & $3.120,67$ & 25,35 & 123,10 \\
\hline PO2 & $\mathrm{R} \$$ & 997,40 & 8,45 & 118,04 \\
\hline PO3 & $\mathrm{R} \$$ & $3.033,17$ & 25,35 & 119,65 \\
\hline PO4 & $\mathrm{R} \$$ & $3.006,09$ & 25,35 & 118,58 \\
\hline PO5 & $\mathrm{R} \$$ & 997,40 & 8,45 & 118,04 \\
\hline PO6 & $\mathrm{R} \$$ & $2.015,77$ & 16,9 & 119,28 \\
\hline PO7 & $\mathrm{R} \$$ & $1.997,09$ & 16,9 & 118,17 \\
\hline Totais & $\mathrm{R} \$$ & $\mathbf{1 5 . 1 6 7 , 6 1}$ & $\mathbf{1 2 6 , 7 5}$ & $\mathbf{1 1 9 , 6 7}$ \\
\hline
\end{tabular}

Para a identificação dos custos hora, bem como a elaboração do Quadro 5, realizou-se a divisão dos custos mensais de cada Posto Operativo (Quadro 4), pelo total do tempo diário trabalhado na organização, conforme recomenda Bornia (2002). Desta forma, para apuração do cálculo, tornou-se necessário observar o tempo total de produção da organização, ou seja, às 8 horas e 45 minutos diários de trabalho. Os resultados encontrados evidenciam o efetivo dispêndio de insumos gastos na linha de produção, por posto operativo, referente ao custo hora de funcionamento da linha de produção.

A próxima etapa realizada no estudo se refere à escolha do produto a ser analisado. Neste caso, optou-se por analisar o produto vidro curvado tipo 1, o qual representa $85 \%$ da produção total da empresa. De posse dessas informações, realizou-se a análise do tempo gasto em cada posto operativo, considerando todas as etapas do processo de produção. Essa variável é muito importante 
na aplicação do método, uma vez que os custos são apropriados aos produtos, em função do tempo gasto em cada etapa da produção dos materiais em estudo. O Quadro 6 apresenta a seguir, o custo do produto base identificado por posto operativo.

\begin{tabular}{|c|r|c|r|}
\hline \multicolumn{6}{|c|}{ Quadro 6 - Apuração do custo do produto base } \\
\hline Código & Custo Hora (R\$) & $\begin{array}{c}\text { Tempo Passagem } \\
\text { (h) }\end{array}$ & $\begin{array}{c}\text { Custo Produto } \\
\text { Base (R\$) }\end{array}$ \\
\hline PO1 & 123,10 & 0,03 & 3,69 \\
\hline PO2 & 118,04 & 0,03 & 3,54 \\
\hline PO3 & 119,65 & 0,044 & 5,26 \\
\hline PO4 & 118,58 & 0,04 & 4,74 \\
\hline PO5 & 118,04 & 0,02 & 2,36 \\
\hline PO6 & 119,28 & 0,0135 & 1,61 \\
\hline PO7 & 118,17 & 0,08 & 9,45 \\
\hline \multicolumn{2}{r|}{} & Total & $\mathbf{3 0 , 6 6 6 8 3 3 2 5}$ \\
\cline { 4 - 5 } & & &
\end{tabular}

Fonte: Dados da pesquisa

O Quadro 6 evidencia os tempos de passagem do produto base pelos postos operativos e o estabelecimento do custo hora base dos produtos, por PO. Para que fosse possível a identificação destes tempos, solicitou-se o auxílio dos colaboradores de cada setor de produção (PO), a fim de identificar o tempo real gasto na fabricação deste produto. Deste modo, também se optou por descartar eventuais erros na análise, em função de tempo gasto com falhas no processo de beneficiamento dos produtos. De acordo com Wernke (2004) os tempos identificados devem se aproximar ao tempo ideal de produção, uma vez que, neste caso, a variável tempo influenciará toda aplicação do método e, por conseqüência, toda a apuração dos custos de produção da empresa.

Desta forma, verifica-se que os custos do produto base identificados no Quadro 6 representam quanto cada posto operativo consome por tempo de passagem, sendo seu valor determinado a partir da multiplicação do custo hora obtido no Quadro 3, pelo tempo total de passagem monitorado nesta fase. Logo, pode-se identificar que a soma de cada posto operativo indicará o custo base total de uma hora de trabalho da empresa.

A próxima etapa realizada na pesquisa refere-se à identificação dos potenciais produtivos. De acordo com Bornia (1995, p. 78), cada posto operativo possui capacidade de gerar (ou repassar) esforço de produção. “A esta capacidade dá-se o nome de potencial produtivo. O potencial produtivo é desta forma, a quantidade de esforço de produção gerada pelo posto operativo quando em funcionamento por uma hora". O Quadro 7 evidencia o potencial produtivo dos postos operativos da empresa pesquisada. 
Quadro 7 - Potenciais produtivos dos PO (UEP/Hora)

\begin{tabular}{|c|r|c|r|}
\hline Código & $\begin{array}{c}\text { Cus to Hora PO } \\
(\mathbf{R} \$ \mathbf{)}\end{array}$ & $\begin{array}{c}\text { Custo Produto } \\
\text { Base (R\$) }\end{array}$ & \multicolumn{1}{c|}{ UEP/Hora } \\
\hline PO1 & 123,10 & 30,66683325 & 4,01 \\
\hline PO2 & 118,04 & 30,66683325 & 3,85 \\
\hline PO3 & 119,65 & 30,66683325 & 3,90 \\
\hline PO4 & 118,58 & 30,66683325 & 3,87 \\
\hline PO5 & 118,04 & 30,66683325 & 3,85 \\
\hline PO6 & 119,28 & 30,66683325 & 3,89 \\
\hline PO7 & 118,17 & 30,66683325 & 3,85 \\
\hline & & Total & $\mathbf{2 7 , 2 2}$ \\
\cline { 4 - 4 } & & &
\end{tabular}

Fonte: Dados da pesquisa

Como se pode observar no Quadro 7, o valor do UEP/hora é obtido através da divisão do custo hora por PO pelo custo total do produto base, identificado no Quadro 6. Desta forma, é possível se identificar quantas unidades de produção cada PO conseguiria gerar, em cada hora trabalhada, considerando-se o tempo ideal de fabricação, também apurado no Quadro 6.

A sexta etapa do processo de implantação do método proposto consiste em estabelecer os equivalentes dos produtos em UEP. Estes por sua vez são obtidos por meio da multiplicação do UEP/hora (Quadro 7), pelo tempo de passagem em cada PO (Quadro 6), identificando-se assim quantas UEP's são consumidas pelo produto, em cada posto operativo. O Quadro 8 apresenta os equivalentes dos produtos em UEP, identificados na pesquisa.

\begin{tabular}{|c|r|c|r|}
\hline \multicolumn{5}{|c}{ Quadro 8 - Equivalente do produto em UEP } \\
\hline Código & UEP/Hora (R\$) & $\begin{array}{c}\text { Tempo Passagem } \\
\text { (h) }\end{array}$ & Equivalente (UEP) \\
\hline PO1 & 4,01 & 0,03 & 0,12 \\
\hline PO2 & 3,85 & 0,03 & 0,12 \\
\hline PO3 & 3,90 & 0,044 & 0,17 \\
\hline PO4 & 3,87 & 0,04 & 0,15 \\
\hline PO5 & 3,85 & 0,02 & 0,08 \\
\hline PO6 & 3,89 & 0,0135 & 0,05 \\
\hline PO7 & 3,85 & 0,08 & 0,31 \\
\hline & & Total & 1,00 \\
\hline
\end{tabular}

Fonte: Dados da pesquisa

Como se pode observar no Quadro 8, em virtude de ter sido analisado apenas um produto (vidro curvado tipo 1), o resultado total do equivalente desse em UEP será um inteiro. Logo, por meio da aplicação da metodologia proposta, é possível a identificação do consumo proporcional dos esforços gastos na produção, em cada posto operativo. A etapa seguinte consiste em identificar o custo de produção (transformação) da empresa em UEP no período, o que passa a ser apresentado no Quadro 9. 
Quadro 9 - Produção total em UEP / Mês

\begin{tabular}{|c|c|c|c|}
\hline Produto & $\begin{array}{c}\text { Quantidade } \\
\text { produzida (pç) }\end{array}$ & UEP & Total de UEP's \\
\hline Virdr. Curv. & 10.552 & 1 & 10.552 \\
\hline
\end{tabular}

Fonte: Dados da pesquisa

Para a conversão da produção da empresa em UEP's, foi necessário inicialmente identificar a quantidade total de vidros curvados tipo 1 beneficiados no período objeto de análise. Esta informação foi disponibilizada pela empresa por meio dos registros que apuram a quantidade mensal produzida deste produto. Assim sendo, identificou-se um beneficiamento total no período analisado de 10.552 unidades de vidros curvados do tipo 1, o que resultou na conversão de 10.552 UEP's, uma vez que se analisou apenas um produto.

Finalmente, após a análise do processo e a apuração dos cálculos necessários à identificação do custo de produção (transformação) da empresa pesquisada em UEP's, torna-se possível a identificação do custo unitário por unidade produzida, em reais, consumidos pela empresa neste período.

\begin{tabular}{|c|c|c|c|}
\hline \multicolumn{4}{|c|}{ Quadro 10 - Custo de produção/transformação em unidades } \\
\hline Produto & $\begin{array}{c}\text { Custo de } \\
\text { Produção R\$ }\end{array}$ & Total de UEP's & Custo em R\$ \\
\hline Virdr. Curv. & $15.167,61$ & 10.552 & 1,437415419 \\
\hline
\end{tabular}

Fonte: Dados da pesquisa

Como se pode observar no Quadro 10, esse valor é obtido a partir da divisão dos custos totais de transformação (Quadro 4), pela produção total em UEP’s (Quadro 9). Assim sendo, verifica-se que a empresa possui um custo total de produção (esforços empreendidos na transformação das matérias primas em produto: vidro curvado do tipo 1), de $\mathrm{R} \$ 1,44$ (um real e quarenta e quatro centavos). Destaca-se que este valor se refere apenas aos custos de transformação da empresa para este produto, não sendo considerados aqui, os custos de aquisição das matérias primas (peças de vidro).

\section{Considerações finais}

Em organizações industriais, informações relacionadas à produção e à gestão de custos são importantes para a avaliação do negócio e a tomada de decisão. Uma avaliação inadequada destes processos pode induzir o gestor a apurar um custo de produção inadequado. Por conseqüência, na ocasião da comercialização destes produtos, a empresa pode obter uma margem menor a desejada ou até mesmo ter prejuízos em determinada transação.

Além disto, torna-se necessário para o gestor identificar se a transformação de insumos em produtos está sendo executada de forma eficiente na organização. Deste modo, para que se possa obter uma boa informação sobre os custos de produção nas organizações, torna-se necessário a 
utilização de uma metodologia de custeio, adequada às necessidades da empresa. De acordo com Bornia (1995), uma das alternativas para apuração dos custos de produção, bem como a avaliação dos processos industriais como um todo é o método de Unidade de Esforço de Produção (UEP).

Neste contexto, este estudo teve por objetivo aplicar o método UEP para mensurar o custo de transformação do produto base, vidros curvados, em uma indústria sediada no município de Venâncio Aires/RS, buscando identificar qual o custo de transformação consumido por esta linha de produtos, na empresa pesquisada.

Para tanto, de forma mais específica, buscou-se: apresentar o método UEP, suas características e abordagem; identificar os elementos de custos relacionados à fabricação de vidros curvados na empresa pesquisada; apurar o custo de transformação destes produtos utilizando o método UEP; e, analisar a contribuição deste método no processo decisório.

Os resultados encontrados indicam que o método UEP pode ser utilizado como método de custeio e proporciona às informações necessárias a identificação dos custos efetivamente gastos na transformação dos insumos em produto final. Os custos mais significativos identificados na fabricação do produto analisado referem-se aos gastos com mão de obra.

Conclui-se que a empresa possui um baixo custo de transformação, o que proporciona uma maior competitividade para a organização. Como recomendação a estudos futuros, sugere-se a aplicação deste estudo nas demais linhas de produção da empresa pesquisada, a fim de identificar se há uma mesma tendência de esforço consumido na fabricação destes produtos.

\begin{abstract}
This study aims to apply the UEP method to measure the cost of processing the product base, curved glass, in an industrial organization, seeking to identify the cost of processing consumed by this product line. The research is characterized as a case study, an exploratory approach with quantitative data. The results indicate that the method can be used as UEP costing system providing the information necessary to identify the costs actually spent on the transformation of inputs into the final product. The most significant costs to manufacture this product are related to spending on labor. We conclude that the company has a low cost of processing, which provides a greater competitiveness for the organization.
\end{abstract}

Key-words: UEP; costing method; cost of processing.

\title{
Referências
}

BORGERT, A.; SILVA, M. Z. Método de custeio híbrido para gestão de custos em uma empresa prestadora de serviços. In: Congresso Internacional de Custos, IX, Itapema, 2005. Anais... Florianópolis: ABC, 2005. CD-ROM.

BORNIA, A. C. A utilização do Método da Unidade de Esforço de Produção na quantificação das perdas internas da empresa. In: Congresso Brasileiro de Gestão Estratégica de Custos, I, São Leopoldo, 1994. Anais... São Leopoldo: Unisinos, 1994.

Mensuração das perdas dos processos produtivos: uma abordagem metodológica de controle interno. Tese (Doutorado em Engenharia da Produção) - UFSC, Florianópolis, 1995. 
Análise gerencial de custos: aplicação em empresas modernas. Porto Alegre: Bookman, 2002.

Análise gerencial de custos: aplicação em empresas modernas. 2. ed. São Paulo: Atlas, 2009.

CAMBRUZI, D.; BALEN, F. V.; MOROZINI, J. F. Unidade de Esforço de Produção (UEP) como Método de Custeio: Implantação de Modelo em uma Indústria de Laticínios. ABCustos Associação Brasileira de Custos - Vol. IV n 1 jan/abr 2009.

FRAGA, M. S.; COUTINHO, W. R.; GIOVANNINI, J. E.; YOSHITAKE, M. Unidade de esforço de produção e utilização do plano-sequência. ABCustos Associação Brasileira de Custos - Vol. IV n 1 - jan/abr 2009.

GANTZEL, G.; ALLORA, V. Revolução dos custos. São Paulo: Qualidade, 1996.

GIL, A. C. Como elaborar projetos de pesquisa. 4. ed. São Paulo: Atlas, 2002.

KLIEMANN NETO, F. J. Gerenciamento e controle da produção pelo Método das Unidades de Esforço de Produção. In: Congresso Brasileiro de Gestão Estratégica de Custos, I, São Leopoldo, 1994. Anais... São Leopoldo: Unisinos, 1994.

OLIVEIRA, H. V.; BEUREN, I. M. Mensuração das atividades empresariais: custeio baseado em atividades x método da unidade de esforço de produção. Revista do Conselho Regional de Contabilidade do Rio Grande do Sul, Porto Alegre, v.25, n.84, p.31-39, jan./mar. 1996.

PEREIRA, F. S.; REBELATTO, D. A. N.; TACHIBANA, W. K. Revisitando o Método das Unidades de Esforço de Produção (Uep's): algumas considerações quanto à sua eficiência e eficácia como instrumento de gestão. In: Congresso Nacional de Custos, VII, Recife, 2000. Anais... Recife: ABC, 2000. CD-ROM.

RICHARDSON, R. J. Pesquisa social: métodos e técnicas. 2. ed. São Paulo: Atlas, 1989.

SAKAMOTO, F. T. K.; ALLORA, V.; OLIVEIRA, S. E. Melhoramento nas ferramentas de gestão: a implantação da Up'- Unidade de Produção - na Seara Alimentos S/A. In: Encontro Nacional de Engenharia de Produção, ENEGEP, Salvador, 2001. Anais... Salvador: ABEPRO, 2001. CD-ROM.

SOUZA, M. A.; DIEHL, C. A. Gestão de custos - uma abordagem integrada entre contabilidade, engenharia e administração. São Paulo: Atlas, 2009.

WALTER, F.; SCHULTZ, C. A.; DANTAS, Y. G. C.; CONFESSOR, K. L. A. O perfil dos artigos sobre o Método das UEPs nos anais do Congresso Brasileiro de Custos e do Encontro Nacional de Engenharia de Produção. In: Congresso Brasileiro de Custos, XVI, Fortaleza, 2009. Anais... Fortaleza: ABC, 2009. CD-ROM.

WERNKE, R. Método da Unidade de Esforço Padrão (UEP). Revista do Conselho Regional de Contabilidade do Rio Grande do Sul, Porto Alegre, v.25, n.84, p.49-56, jan./mar. 1996.

Gestão de Custos: uma abordagem prática. 2. ed. São Paulo: Atlas, 2004.

\section{Dados dos autores:}

Nome completo: Vinícius Costa da Silva Zonatto

Filiação institucional: FURB - Universidade Regional de Blumenau

Departamento: PPGCC - Programa de Pós Graduação em Ciências Contábeis

Função ou cargo ocupado: Doutorando em Ciências Contábeis e Administração

Endereço completo para correspondência (bairro, cidade, estado, país e CEP): Rua Barros Cassal, n. 292 - B. Ipiranga - CEP 99.300-000 - Soledade/RS.

Telefones para contato: (51) 2106-6369 / (51) 8538-5584

e-mail: viniciuszonatto@gmail.com

Nome completo: Márcia Zanievicz da Silva

Filiação institucional: FURB - Universidade Regional de Blumenau 
Departamento: PPGCC - Programa de Pós Graduação em Ciências Contábeis

Função ou cargo ocupado: Doutoranda em Ciências Contábeis e Administração

Endereço completo para correspondência (bairro, cidade, estado, país e CEP): Universidade Regional de Blumenau, Programa de Pós Graduação em Ciências Contábeis, Rua Antônio da Veiga, n. 140 - Caixa Postal n. 1507 - B. Victor Konder, CEP: 89.012-900 - Blumenau/SC.

Telefones para contato: (47) 3321-0938

e-mail:marciaza@gmail.com

\section{Nome completo: Jorge Ribeiro de Toledo Filho}

Filiação institucional: FURB - Universidade Regional de Blumenau

Departamento: PPGCC - Programa de Pós Graduação em Ciências Contábeis

Função ou cargo ocupado: Professor - Doutor em Controladoria e Contabilidade (USP)

Endereço completo para correspondência (bairro, cidade, estado, país e CEP): Universidade Regional de Blumenau, Programa de Pós Graduação em Ciências Contábeis, Rua Antônio da Veiga, n. 140 - Caixa Postal n. 1507 - B. Victor Konder, CEP: 89.012-900 - Blumenau/SC.

Telefones para contato: (47) 3321-0938

e-mail: jtoledo@furb.br

Nome completo: Andréa Valderene Drebes

Filiação institucional: FDA - Faculdade Dom Alberto

Departamento: Coordenação de Pós Graduação

Função ou cargo ocupado: Curso de Especialização em Gestão Empresarial

Endereço completo para correspondência (bairro, cidade, estado, país e CEP): Faculdade Dom Alberto, Curso de Especialização em Gestão Empresarial, Rua Ramiro Barcelos, n. 892 - B. Centro, CEP: 96.810-054 - Santa Cruz do Sul/RS.

Telefones para contato: (51) 2106-6369

e-mail: andreadrebes@domalberto.edu.br

Enviado em: 25/02/2011

Aprovado em: 22/03/2012 